\author{
Pasquale Pasquino* \\ New York University (New York, EE.UU.) \\ pp14@nyu.edu
}

\title{
¿Cómo deciden las Cortes Constitucionales? ?** $^{*}$
}

\author{
How do the Constitutional Courts decide?
}

Como são tomadas as decisões nas

Cortes Constitucionais?

Artículo de investigación: recibido 25/08/2016 y aprobado 17/11/2016

\footnotetext{
* Es senior research fellow en el Centre National de la Recherche Scientifique de París y Distinguished Professor in Politics and Law en NYU (New York University).

** Traducción de Vicente F. Benítez R. (Universidad de La Sabana, Colombia), quien agradece al autor su generosidad y su guía durante el proceso de traducción.
} 



\title{
Resumen
}

El propósito de este artículo es explorar el modo de producción de las sentencias judiciales redactadas por cortes constitucionales en Europa. El objeto de estudio natural de la teoría constitucional es el análisis de este producto final de creación judicial de Derecho por Cortes Constitucionales. Sin embargo, la doctrina no ha prestado suficiente atención, desde una perspectiva de derecho comparado, a los mecanismos y procedimientos que conducen a las decisiones de estas instituciones. Así, este documento hará una clasificación de los diferentes tipos de procesos decisionales en las cortes, analizando las etapas que conforman «el modo de producción», a partir del estudio de las decisiones de la Corte Suprema de Estados Unidos, el Consejo Constitucional francés, la Corte Constitucional italiana y la Corte Constitucional alemana. Al final del documento se formulan algunas conclusiones sobre el periodo de los magistrados, su filiación partidista, las restricciones temporales de deliberación y factores institucionales como el número de asistentes o la personalización de sus miembros.

Palabras clave: Decisiones de las cortes constitucionales; deliberación en las cortes constitucionales; adjudicación constitucional; derecho comparado de cortes constitucionales.

\begin{abstract}
The purpose of this article is to explore the mode of production of judicial sentences drafted by constitutional courts in Europe. The natural object of study of the constitutional theory is the analysis of this final product of judicial creation of Law by Constitutional Courts. However, the doctrine has not given sufficient attention -from a comparative law perspective- to the mechanisms and procedures that lead to the decisions of these institutions. Thus, this document will classify the different types of decision-making processes in the courts, analyzing the stages that make up the «mode of production», from the study of the decisions of the Supreme Court of the United States, the Constitutional Council of the French Republic, The Constitutional Court of Italy and the Federal Constitutional Court of Germany. At the end of the paper, some conclusions are made about the period of the magistrates, their party affiliation, the temporary restrictions of deliberation and institutional factors such as the number of attendees or the personalization of its members.
\end{abstract}

Keywords: Decisions of the constitutional courts; Deliberation in the constitutional courts; Constitutional adjudication; Comparative law of constitutional courts. 


\section{Resumo}

O propósito deste artigo é explorar o modo de produção das sentenças judiciais jurídicas redigidas por cortes constitucionais na Europa. $\mathrm{O}$ objeto de estudo natural da teoria constitucional é a análise deste produto final de criação judicial de Direito por Cortes Constitucionais. Contudo, a doutrina não tem prestado a devida atenção, desde uma perspectiva de direito comparado, aos mecanismos e procedimentos que conduzem às decisões destas instituições. Assim, este documento fará uma classificação dos diferentes tipos de processos de decisões nas cortes, analisando as etapas que conformam «o modo de produção», a partir do estudo das decisões da Corte Suprema dos Estados Unidos, o Conselho Constitucional francês, a Corte Constitucional italiana e a Corte Constitucional alemã. Ao final do documento se fazem algumas conclusões sobre o período dos magistrados, sua filiação partidária, as restrições temporárias de deliberação e fatores institucionais como o número de assistentes ou a personalização de seus membros.

Palavras chave: decisões das cortes constitucionais; deliberação nas cortes constitucionais; adjudicação constitucional; direito comparado de cortes constitucionais. 


\section{Introducción}

El propósito de este artículo es explorar el modo de producción de normas jurídicas (Entscheidungen, sentencias, sentenze, opinions) redactadas por cortes constitucionales en Europa.

El objeto de estudio natural de la teoría constitucional es el análisis (y algunas veces la crítica) de este producto final de creación judicial de Derecho por Cortes Constitucionales. Sin embargo, la doctrina no ha prestado suficiente atención, desde una perspectiva de derecho comparado, a los mecanismos y procedimientos que no sólo son el origen, sino que conducen a las decisiones de estas importantes instituciones. Incluso el reciente e interesante debate, acerca de la legitimidad de la creación judicial de Derecho que resulta de la adjudicación constitucional, ha generalmente evitado reflexionar sobre cómo se producen estas decisiones.

En este texto se hace un intento parcial por clasificar diferentes tipos de procesos decisionales en las cortes, analizando las etapas que conforman «el modo de producción» de sus decisiones, y de manera más detallada el caso de tres Cortes que ejemplifican las variantes básicas de estos modos de producción.

Primero haré un bosquejo, desde un punto de vista típicamente ideal, de las más importantes modalidades de remisión de casos a la Corte. Esto es importante teniendo en cuenta que las reglas de legitimidad por activa -o de acceso a la Corte- son esenciales para entender la forma en la institución opera, dado que dichas reglas determinan, entre otros aspectos, el número de casos que reciben, así como los temas que cada Corte abordará.

La segunda sección presenta los procedimientos de toma de decisión de tres Cortes europeas importantes, representativas y muy peculiares, ${ }^{1}$ utilizando a la Corte Suprema de Justicia de los Estados Unidos como punto de referencia para comparar el procedimiento decisional de las cortes constitucionales del viejo continente con el procedimiento adoptado por esta antigua institución americana. ${ }^{2}$

Además, en esta sección me concentraré en el rol de los asistentes legales (law clerks) al interior de estas instituciones y mostraré su muy importante -pero a menudo ignorada- contribución al proceso decisional de las Cortes.

\footnotetext{
1 Es interesante notar que la estructura de la Corte Constitucional alemana ha influenciado muchas constituciones recientes, no sólo en Europa (España o Polonia), sino también más allá del viejo continente (Corea del Sur). El modelo francés ha impactado principalmente constituciones no europeas: África Occidental por razones obvias, pero también Chile.

2 Un primer intento desde esta perspectiva se encuentra en Kelsen (1942).
} 
Una vez hecho esto, presentaré una breve conclusión donde trataré de proponer algunas lecciones normativas con respecto a los mecanismos por medio de los cuales operan las Cortes, y al modo de producción de sus decisiones.

1.

«Of the greatest importance is the question: in what way can proceedings in the constitutional court be initiated? The extent to which the constitutional court will be able to fulfill its task as a guarantor of the constitution depends primarily on the regulation of this question».

Hans Kelsen ${ }^{3}$

Las Cortes Constitucionales son instituciones que producen derecho judicial. ${ }^{4} \mathrm{~A}$ primera vista esta forma de producción jurídica -Rechtserzeugung, en lenguaje Kelseniano-contradice un principio clásico de cualquier gobierno representativo (el régimen político que hoy llamamos democracia): un sistema caracterizado por la ideología de acuerdo con la cual únicamente los órganos del estado elegidos pro tempore, a través de elecciones populares y controlables electoralmente por parte de los votantes son los únicos autorizados, y por lo tanto los únicos con la autoridad de imponer a los ciudadanos decisiones colectivas obligatorias, típicamente con la forma de normas jurídicas.

Los integrantes de estas altas cortes no son elegidos por los ciudadanos ni controlables por ellos (en general, además, no pueden ser reelegidos, aunque hay, como es usual, algunas excepciones). ${ }^{5} \mathrm{~A}$ pesar de esto, dichos jueces toman decisiones que deben ser obedecidas por los ciudadanos y otros órganos 14 estatales de una forma idéntica a las leyes aprobadas por funcionarios elegidos y controlables en los parlamentos. Se debe anotar, en todo caso, que un punto clave $^{6}$ radica en que el procedimiento de toma de decisiones judiciales es profundamente diferente del que se usa por las asambleas representativas en el Parteienstaaten (sistema político dominado por partidos políticos).

3 Wesen und Entwicklung der Staatsgerichtsbarkeit, (1928)

4 M. Cappelletti, Giudici legislatori, Giuffrè, 1984.

5 Por ejemplo, la República Checa (donde los jueces son nombrados por periodos renovables de 10 años; actualmente dentro de sus 15 miembros parece que sólo el presidente ha sido reelegido), y el Tribunal de Justicia de la Unión Europea (donde los jueces son elegidos por un término renovable de 6 años).

6 Ver M. Cappelletti, Giudici legislatori. 
En ese contexto, los procedimientos que las instituciones objeto de este artículo usan para producir derecho (Recht) pueden ayudar a evaluar su legitimidad ${ }^{7} \mathrm{o}$, al menos, presentar algunas sugerencias normativas respecto de su modus operandi.

Antes de presentar estos procedimientos parece útil decir unas pocas palabras acerca de qué es lo que hacen las cortes. Luego, voy a analizar cómo lo hacen.

Las Cortes Constitucionales, se nos ha dicho, tienen la función de controlar la jerarquía de las normas, interpretar la constitución y, si son cortes efectivas, ser un obstáculo al ejercicio ultra vires y abusivo del poder, así como de la violación de derechos constitucionalmente protegidos.

La metáfora espacial que fue desarrollada a comienzos del siglo XX por la Escuela Jurídica austríaca, notablemente por Adolf Julius Merkl ${ }^{8}$ y Hans Kelsen -y que no es idéntica a la cláusula de supremacía estadounidense ${ }^{9}$, la cual es equivalente al principio alemán de la Constitución de Weimar Reichsrecht bricht Landesrecht ${ }^{10}$ - pareciese transmitir simplemente el concepto de una jerarquía en las normas que tiene que ser usado sistemáticamente para justificar la adjudicación constitucional. Sería mejor y menos erróneo conectar el control judicial de la legislación primaria con la rigidez de la Constitución, ${ }^{11}$ que representa un intento por establecer un gobierno limitado en una sociedad moderna legalmente igualitaria. ${ }^{12}$ Sea como fuere, la interpretación, y más específicamente la interpretación constitucional, va más allá de la aplicación de un silogismo práctico en el cual el artículo constitucional es la premisa mayor, la ley analizada la menor, y la decisión judicial la conclusión lógico-mecánica. La mayoría de los académicos y muchos jueces constitucionales concuerdan

7 No es posible discutir aquí el significado de este término y los argumentos a favor de una democracia constitucional (verfassungsmäßiger Rechtstaat). Lo que el texto busca sugerir es que tener en cuenta los procedimientos decisionales puede no sólo ampliar, sino hacer que el debate acerca de la legitimidad de Cortes Constitucionales/Supremas sea mucho más interesante y más cercano a la verdadera forma en la cual esas instituciones operan.

8 «Prolegomena einer Theorie des rechtlichen Stufenbaus», En: Verdross, A (1967, p.252-294).

9 La Cláusula de Supremacía de la Constitución de los Estados Unidos (Artículo VI, cláusula 2) establece que la Constitución, las leyes federales aprobadas de conformidad con ella, y los tratados celebrados bajo su autoridad constituyen la norma suprema de la nación.

10 Ver el artículo 13 de la Constitución de Weimar.

11 Ver Bryce, J. .. Y además: Pasquino, P. (2016, p.121-136).

12 En sociedades premodernas no igualitarias la estructura de un gobierno limitado se basaba en la doctrina clásica de la constitución mixta (memigmene politeia, Aristóteles - republica, Maquiavelo). 
hoy en día en afirmar que la adjudicación judicial implica la producción de derecho por medio de la interpretación de la constitución. ${ }^{13}$ La interpretación constitucional es, a menudo, únicamente producción de derecho. En cualquier caso, para entender en qué sentido específico y cómo estas cortes de cierre son productoras de Derecho o colegisladoras, necesitamos observar -para empezar y seguir con la sugerencia de Kelsen- un mecanismo procedimental esencial: quién puede remitir casos a la Corte Constitucional, o en palabras de Franz Kafka, quién puede abrir las puertas de estas Cortes. De una forma menos literaria, en un lenguaje jurídico decimos que las Cortes Constitucionales son órganos pasivos; estos no pueden tomar la iniciativa, y se requiere una petición, lo cual es una diferencia importante con respecto a los Parlamentos elegidos y controlables.

\section{Acceso}

Típicamente, y de una manera simplificada, tres actores distintos pueden abrir la puerta de una Corte Constitucional (particularmente en estados europeos, a diferencia de los Estados Unidos):
A. Actores/funcionarios políticos/institucionales (i.e. elegidos)
B. Jueces
C. Litigantes

A) Los casos más comunes de remisión por parte de actores políticos/ institucionales son (1) los representantes de los Länder (en general las subunidades políticas de un sistema federal o cuasi-federal: regiones, provincias o estados) o el gobierno central; y (2) una minoría de los miembros del Parlamento, como ocurre notablemente en el caso del sistema constitucional francés. Estos son, claramente, dos actores muy diferentes. ${ }^{14}$ En el primer caso, la Corte Constitucional es un juez federal, una institución que ejerce una función que es inevitable en cualquier sistema federal. De hecho, en el Sacro Imperio Romano

\footnotetext{
13 Algunos datos, ya un poco antiguos, que soportan esta afirmación para el caso de Tribunal Constitucional Federal Alemán pueden verse en Landfried, Ch. (1996).

14 Hay ciertamente otros actores políticos que deben ser considerados en una clasificación exhaustiva: Presidentes de la República y, como ocurre en Francia, los presidentes de las dos cámaras del Parlamento y el Primer Ministro.
} 
ya existía una Corte a cargo de decidir litigios similares, el Reichskammergericht. ${ }^{15}$ En Australia hay una Corte federal semejante, ${ }^{16}$ mientras que en Europa se debe mencionar el Tribunal Federal Suizo. ${ }^{17}$ Vale la pena recordar que este tipo de adjudicación federal se encuentra también en el origen del rol de la Corte Suprema de los Estados Unidos. ${ }^{18}$ En estos casos la función de la Cortes es, por un lado, impedir que el sistema federal colapse en un estado unitario $y$, por el otro, asegurar que las subunidades no se independicen jurídicamente del régimen federal.

Debido a su singularidad en Europa ${ }^{19}$ es particularmente interesante el caso del llamado saisine parlementaire francés. Este mecanismo de remisión, introducido en su versión minimalista en la constitución de la Quinta República, permite, gracias a la reforma constitucional de 1974, que un mínimo de 60 senadores o miembros de la Asamblea Nacional soliciten al Consejo Constitucional que revise una ley aprobada por la mayoría antes de su promulgación. La singularidad ${ }^{20}$

15 La referencia obligada es todavía Smend, R. (1911) (Neudruck. Scientia, Aalen 1965). En relación con la corte federal austríaca antes de la creación del Tribunal Constitucional (Verfassungsgerichtshof) en 1920, ver Eisenmann, Ch. (1986). Durante la República de Weimar existió una Corte a cargo de la adjudicación federal, el Staatsgerichtshof en Leipzig, conocido especialmente por el juicio Preussen contra Reich, el cual en 1932 precipitó el colapso de la República. Sobre esta Corte ver: Gotthard, J. (1963), y Wehler, W. ((1979).

16 Patapan, H. (2000).

17 Esta importante y antigua Corte (Bundesgericht) generalmente no tiene competencia de adjudicación constitucional, sino que es el árbitro que decide los litigios entre los cantones y la federación (Art. 189.4 de la Constitución: «Les actes de l'Assemblée fédérale et du Conseil fédéral ne peuvent pas être portés devant le Tribunal fédéral. Les exceptions sont déterminées par la loi». La Constitución cierra la posibilidad de analizar actos del Parlamento Federal, a menos que la ley autorice dicha revisión).

18 Ver Rakove, J. (1997).

19 El artículo 61 de la Constitución de Francia dispone: «Las leyes orgánicas, antes de su promulgación, las proposiciones de ley mencionadas en el artículo 11 antes de que sean sometidas a referéndum, y los reglamentos de las Cámaras parlamentarias, antes de su aplicación, deberán ser sometidos al Consejo Constitucional, el cual se pronunciará sobre su conformidad con la Constitución. Con el mismo fin, podrán presentarse las leyes al Consejo Constitucional antes de su promulgación por el Presidente de la República, el Primer Ministro, el Presidente de la Asamblea Nacional, el Presidente del Senado o sesenta diputados o sesenta senadores». Esta última frase fue agregada por una reforma constitucional en 1974.

20 El libro de Alec Stone sobre el Consejo Constitucional francés, The birth of judicial politics in France: the Constitutional Council in comparative perspective (Stone, 1992), produjo dentro de la academia norteamericana la impresión errónea según la cual el modelo francés es típicamente el 
radica en la elección de un control ex ante, lo cual permite salvaguardar el mito francés de la loi expression de la volonté générale. ${ }^{21}$

Nótese que en este caso el Consejo Constitucional -los políticos franceses aún se resisten a llamarlo «Corte» a pesar de la reforma constitucional de 2008- funciona como un cuerpo intermedio (Montesquieu utilizó esta expresión refiriéndose a los Parlamentos del ancien régime -que en realidad eran Altas Cortes de Justicia, ${ }^{22}$ no asambleas representativas - y fue repetida por el federalista 78) ${ }^{23}$ entre la mayoría y la minoría en el parlamento en el mismo momento de redactar las leyes, esto es, cuando la ley es aprobada por la mayoría, pero no promulgada por el Presidente de la República en el Bulletin Officiel. El Conseil Constitutionnel asume en este caso el rol de un mecanismo de balance entre el partido o coalición que triunfa en la elección y el(los) perdedor(es), evitando una situación en la cual la relación entre estos se vuelva una de todo o nada: todo el poder a la mayoría, ningún poder a las minorías. ${ }^{24}$

Dentro de esta primera categoría de remisiones hay una muy importante que ocurre en el caso de lo que llamamos conflictos entre altos órganos del estado: Organstreitigkeit en alemán, conflitti di attribuzione en italiano, conflictos entre órganos constitucionales del Estado en castellano. ${ }^{25}$ La democracia

europeo. En realidad este modelo es propio únicamente de Francia. Una pequeña historia de la adjudicación constitucional francesa puede verse en Pasquino (2009).

21 Debido a que la Constitución era, como la loi, una expresión de la voluntad general, la única posibilidad de controlar la loi (la decisión de la mayoría parlamentaria) era antes de que ésta existiese en las gacetas legislativas, es decir, antes de su nacimiento a la vida jurídica.

22 Ver la entrada Parlement/Parlements por Rebecca Kingston: http://dictionnaire-montesquieu. ens-lyon.fr/en/article/1377636897/en/

23 Hamilton (2001) señala que: Es mucho más racional entender que los tribunales han sido concebidos como un cuerpo intermedio entre el pueblo y la legislatura, con la finalidad, entre otras varias, de mantener a esta última dentro de los límites asignados a su autoridad (p.332).

24 El argumento de que la moderación -entendida como un límite al gobierno, siguiendo a Montesquieu-podría ser producida simplemente por medio de elecciones competitivas, y de rotación en el poder, no es suficientemente persuasivo por múltiples razones. Primero, la rotación en el poder en una democracia es únicamente una posibilidad, algunas veces se debe esperar muchos decenios, como en Italia, Japón, Noruega, y Suecia. En segundo lugar los abusos de la mayoría pueden ocurrir en cualquier momento; por ejemplo, desde el comienzo mismo de la legislatura. En ese caso esperar cuatro años para la próxima elección no parece ser una perspectiva muy atractiva para los derechos de los ciudadanos.

25 Yo sugeriría que la atribución original del Consejo Constitucional Francés fue una suerte de competencia de Organstreitigkeit: delimitar las fronteras entre las competencias del legislativo y del ejecutivo, que se encuentran establecidas en el artículo 34 de la Constitución de la Quinta República. 
constitucional es un sistema de poder compartido/dividido no solamente de manera vertical, como en los regímenes federales, sino también horizontalmente entre las diferentes ramas que ejercen autoridad política en el nivel central. ${ }^{26}$ Si un conflicto surge entre ellas en relación con sus respectivas competencias, el mecanismo existente para su resolución es ventilar el caso ante la Corte Constitucional, por ejemplo en el supuesto de una disputa entre el Parlamento y el gobierno; como ocurre también con el caso ya mencionado de los conflictos entre regiones, Länder, etc., o entre ellos y el gobierno nacional. En estos casos la Corte actúa como el órgano que tiene la tarea de mantener el balance entre los diferentes órganos con autoridad política, y de proteger la estructura poliárquica/ pluralista del orden constitucional. Claramente este balance depende también de la estructura que la constitución correspondiente le confiere al principio de separación de poderes, que no es el mismo en Alemania o en Italia frente al contenido en la Constitución de la V República francesa. ${ }^{27}$

B) Cuando la remisión proviene de jueces ordinarios, como es el caso del ricorso incidentale italiano, el konkrete Normenkontrolle alemán y, desde 2010 la QPC francesa (acrónimos en francés para question prioritaire de constitutionalité), ${ }^{28}$ el

26 Esta distribución de autoridad política entre diferentes órganos del estado no es, actualmente, el equivalente de la distinción de funciones (legislativa, ejecutiva, judicial) como en la doctrina clásica de Montesquieu. Tampoco es, como lo leemos en el mismo capítulo 6 del libro XI del Espíritu de las Leyes, la distribución del poder legislativo soberano entre los diferentes órganos: el Rey, los Lores, los Comunes como expresión de las premodernas «partes constitutivas de la sociedad». A diferencia de la sociedad premoderna, la distribución contemporánea del poder creador del Derecho en una democracia constitucional es aquella entre órganos elegidos y la Corte Constitucional/ Suprema, donde la Corte tiene también la competencia de árbitro de conflictos estructurales, que son inevitables en constituciones que son «contratos incompletos» que provocan conflictos interpretativos.

27 No se puede subestimar solamente la relación entre la adjudicación constitucional y la arquitectura institucional, sino que también debe tenerse en cuenta la relación entre aquella y el contenido de la constitución. Aunque es cierto que la interpretación constitucional es producción jurídica creadora de Derecho, esto no significa que una Corte Constitucional en una democracia liberal pueda decir cualquier cosa que a bien tenga. Así, por ejemplo, no podría concluir que una ley que elimina la libertad de expresión es constitucional, ni tampoco podría concluir, en un estado claramente secular, que usar una manta para cubrir la cabeza de las mujeres es constitucionalmente permisible si la constitución de dicho estado claramente establece la prohibición de usar mantas en espacios públicos. Si los jueces deciden abiertamente en contra de un artículo constitucional claro, asumen un alto riesgo: el riesgo de que sus atribuciones sean recortadas o suprimidas.

28 Este mecanismo de remisión, como el anterior, existe también en el sistema constitucional de muchos otros estados europeos, como es el caso de España. Ver artículo 53.2 de la Constitución española. 
rol de la Corte es el de servir de contrapoder o, más exactamente, ejercer un control sobre los legisladores elegidos ${ }^{29}$ (tanto presentes como pasados) adicional al de las elecciones. Se trata de un control ejercido sobre las leyes una vez éstas se manifiestan mediante su ejecución/aplicación concreta, lo cual es difícil de anticipar por medio de un control ex ante como el que se desarrolla por el saisine parlementaire. ${ }^{30}$ En Italia esta forma de remisión ha sido, desde sus inicios (1956), y hasta hace poco, el modo esencial de remisión en términos estadísticos y sustanciales. Las cortes ordinarias formulan preguntas preliminares antes de tomar cualquier decisión sobre el caso que deben resolver. Este procedimiento, con el correr del tiempo, ha producido una suerte de correspondencia entre las Cortes ordinarias y la Corte Costituzionale, que en Italia, como en Francia, de acuerdo con la Constitución no hace parte de la rama judicial. Ésta es una solidaridad que representa el verdadero control en un sistema parlamentario en el cual no existen las objeciones presidenciales, y en el que, como en Italia, el bicameralismo no funciona como un contrapoder debido a que, por una parte, las dos cámaras han sido controladas casi siempre por la misma mayoría política y, por la otra, un «gobierno dividido» (mayorías diferentes en la Cámara y en el Senado) no es posible o produciría un ejecutivo cuasi-paralizado en un sistema parlamentario en el cual ambas Cámaras tienen voto de confianza. Lo que se acaba de referir no necesariamente sucede en el caso del konkrete Normenkontrolle alemán. En Italia, el juez a quo normalmente necesita demostrar que existe alguna duda razonable (la non manifestza infondatezza) en relación con la ley que debería aplicar para resolver el conflicto que debe juzgar. En el caso alemán, el juez debe argumentar de una forma más exigente la inconstitucionalidad de la ley.

20 Esta tarea argumentativa puede estar incluso en cabeza de la parte perdedora, que puede interponer una queja constitucional en la Corte Constitucional alemana que, a su turno, puede revocar la sentencia del juez ordinario, lo cual casi nunca ocurre en Italia.

C) El epítome del último caso -la remisión por parte de litigantes o por individuos- es la Verfassungbeschwerde alemana; ${ }^{31}$ es decir, la queja constitucional (existente también en otros estados europeos, particularmente en España bajo

29 En este caso es posible hablar de accountability horizontal, en contraste con la vertical ejercida por voto popular. Al respecto véase Pasquino (2015, p. 157-169)

30 El saisine parlementaire, dicho sea de paso, sólo le confiere a los políticos elegidos popularmente el monopolio para activar el control de constitucionalidad.

31 Ver Lübbe-Wolff, G. (2006, p. 61-88). 
la forma de recurso de amparo) ${ }^{32}$ que le permite al ciudadano recurrir a la Corte Constitucional Federal de Alemania para controvertir una decisión jurídica, o cualquier otra acción de un órgano estatal que pueda infringir los derechos fundamentales garantizados por la Ley Fundamental de Bonn a los ciudadanos, y a cualquier otra persona cuyos derechos sean quebrantados por órganos del Estado alemán. En este escenario la Corte actúa como el guardián de última instancia de los derechos constitucionalmente protegidos: un mecanismo de defensa que adquirió particular importancia en la Alemania de la segunda posguerra.

Dos anotaciones deben agregarse sobre este punto. Primero: a la luz de lo dicho hasta acá, es posible observar cómo las Cortes Europeas supranacionales (i.e. el Tribunal de Justicia de la Unión Europea en Luxemburgo y el Tribunal Europeo de Derechos Humanos en Estrasburgo) tienen mecanismos de remisión semejantes a los analizados. El tercer tipo de remisión, aquel cuyo objetivo es la protección de los derechos contenidos en la Convención Europea de Derechos Humanos, puede ser enviado a la Corte en Estrasburgo como una forma de apelación, después de haber agotado todos los recursos internos. Los otros dos mecanismos de remisión (i.e. A y B) garantizan el acceso a la Corte en Luxemburgo.

Segunda anotación. Algunas de estas cortes nacionales o supranacionales, y notablemente aquellas con «remisión directa», usualmente reciben un gran número de remisiones, como es el caso del Tribunal Europeo de Derechos Humanos, ${ }^{33}$ la Corte Constitucional Federal de Alemania, ${ }^{34}$ y el Tribunal Supremo brasileño. ${ }^{35}$ Para evitar ser sobrepasados por estos números, estas cortes han establecido, gradualmente, mecanismos internos de filtración. Es importante llamar la atención sobre la diferencia entre reglas internas y externas de filtración de casos, así como sobre las reglas formales e informales. Una regla clásica de filtración interna formal es la llamada «regla de los cuatro», inferior a la mayoría de los nueve miembros, la cual ha sido establecida en algún punto en la Corte

32 Ver artículos 14 al 29 y 30-2 de la Constitución de España.

33 «En 2015 40,650 aplicaciones fueron asignadas para decisión judicial, una disminución general del 28\% comparada con 2014 (56,200)». Traducción no oficial de Analysis of statistics 2015, p. 4. Ver http://echr.coe.int/Documents/Stats_analysis_2015_ENG.pdf

345.891 remisiones en 2015. Ver http://www.bundesverfassungsgericht.de/DE/Verfahren/ Jahresstatistiken/2015/gb2015/A-I-2.pdf?_blob=publicationFile\&v=1

35 En 2004 se presentaron 83,667 solicitudes. Ver Jardim de Santa Cruz Oliveira, M. A. (2006, p. 127). 
Suprema de Justicia de los Estados Unidos, y su mecanismo de certiorari, ${ }^{36}$ que en Español significa escoger y seleccionar los casos para decidir. Es bien sabido que la Corte Suprema es una corte de apelación (con muy pocas excepciones), ${ }^{37}$ y que si no decide pronunciarse sobre un caso, no existe denegación de justicia debido a que el control judicial no se concentra ni está monopolizado por la Corte Suprema. Aunque las Cortes Constitucionales europeas deben decidir todos los casos o cuestiones que se les presentan, aquellas con una gran cantidad de casos han establecido una división interna del trabajo ${ }^{38}$ (aunque no ha sido así en Francia e Italia), así como mecanismos informales internos cuyo propósito es evitar «la muerte por su propio éxito».

La importancia del número de casos tiene un impacto relevante en el proceso decisional de las cortes desde dos puntos de vista: la división de trabajo entre los jueces y el rol de sus asistentes.

La reforma constitucional francesa de 2008/2010 escogió una estrategia preferente para seleccionar los casos a ser decididos por el Consejo Constitucional. En el sistema jurídico francés las cuestiones de constitucionalidad formuladas por una parte del juicio son filtradas tanto como por el juge $d u$ fond (el juez del caso en el cual la pregunta es presentada por los litigantes) como por los miembros de las llamadas Hautes Juridictions, esto es, las cortes supremas del ordre judiciaire y del ordre administratif: la Cour de Cassation y el Conseil d'Etat respectivamente. Las razones detrás de esta escogencia, que puede ser catalogada como un filtro externo, son objeto de especulación, pero hay un consenso significativo entre los académicos sobre la tesis de que esta elección tenía la doble función de, primero, ofrecer un rol a las dos cortes más antiguas y poderosas de la República

22 Francesa y, segundo, evitar que el Conseil Constitutionnel se convirtiese en un

36 La «regla de los cuatro» no se encuentra en la Constitución, ni en ninguna ley; ni incluso en las reglas de la Corte. Se trata de una costumbre que ha sido seguida desde que se le otorgó a la Corte la discreción de seleccionar cuáles apelaciones decidir en virtud del Judiciary Act de 1891, del Judiciary Act de 1925, y del Supreme Court Case Selections Act de 1988.

El mecanismo de certiorari se regula en el artículo 14 de las Reglas de la Corte Suprema de Justicia de los Estados Unidos, Parte III, Jurisdicción en el Writ de Certiorari (https://www.law.cornell.edu/ rules/supct/rule_14).

37 La llamada jurisdicción original se encuentra en el artículo III.2 de la Constitución estadounidense. A este respecto se afirma que: «En todos los casos relativos a embajadores, otros ministros públicos y cónsules, así como en aquellos en que sea parte un Estado, el Tribunal Supremo poseerá jurisdicción en única instancia. En todos los demás casos el Tribunal Supremo conocerá en apelación».

38 Particularmente la Corte alemana y el Tribunal Constitucional español establecieron subsecciones al interior de ellas (Kammer y Salas) para enfrentar la gran cantidad de quejas constitucionales. 
órgano muy poderoso, en el sentido de otorgarle el control integral sobre los casos que deberían hacer parte de su expediente.

Este último comentario sirve como puerta de entrada a un segundo conjunto de observaciones.

2.

Modo de producción, o cómo las Cortes Constitucionales desarrollan sus tareas, cómo producen sus normas jurídicas, que reciben nombres distintos en diferentes idiomas: Entscheidungen, sentenze, décisions, opinions, sentencias etc.

Una vez sabemos quién está habilitado para abrir la puerta de la Corte, y una vez ésta se encuentra abierta, es posible tener una idea sobre qué es lo que hacen las Cortes. La siguiente pregunta es: ique pasa detrás de las puertas cerradas de estas instituciones? ¿Cómo producen las decisiones que «salen» por la misma puerta después de su protocolo interno decisional? Los casos o cuestiones se envían al guardián del orden constitucional y sus decisiones «salen» del edificio de la Corte. Pero iqué pasa adentro?, icómo se producen estas decisiones? Éste es el principal tema de investigación que es importante elaborar. Los académicos deben hacer un mayor esfuerzo que en el pasado para observar al interior de lo que Latour (2004) llamó hace unos años refiriéndose al Conseil d'Etat, La fabrique du droit.

En este artículo solo puedo referirme a unos cuantos aspectos. Primero que todo, creo que para entender el procedimiento y el protocolo decisional de las Cortes debemos distinguir dos tipos de Cortes encargadas de la adjudicación constitucional: cortes plurales y cortes colegiales. Ésta no es una distinción estándar, así que explicaré lo que estoy tratando de decir. ${ }^{39}$

La Corte Suprema de Justicia de los Estados Unidos es el ejemplo más revelador de lo que puede ser clasificado como una corte plural. Sin embargo, en tanto que todas las altas cortes están compuestas por paneles (i.e. varios miembros) por oposición a aquellos tribunales caracterizados por tener un solo juez, es necesario definir lo que intento transmitir con la distinción entre corte plural v. corte colegial. La forma más sencilla de explicar esta dicotomía es la afirmación según la cual es importante distinguir aquellas cortes que hablan con una sola voz (gracias al carácter reservado de los votos de sus miembros),

39 Este punto es desarrollado en mi artículo «E pluribus unum: Disclosed and Undisclosed Votes in Constitutional/Supreme Courts», en Elster, J. (2015, p.196-208). 
de aquellos tribunales en los que los magistrados tienen una clara personalidad pública, y quienes tratan de «enseñar desde la magistratura», refiriéndose a individuos específicos del público externo por medio de las opiniones disidentes (o salvamentos de voto), o concurrentes (aclaraciones de voto).

Las Cortes Constitucionales de Austria, Italia, Francia y Bélgica, así como el Tribunal de Justicia de la Unión Europea en Luxemburgo son ejemplos de lo que denomino cortes colegiales, mientras que la mayoría de las cortes del antiguo Commonwealth británico son cortes plurales. Alemania y los estados que se inspiran en el modelo de su Corte Federal podrían ser clasificados como modelos mixtos, puesto que el uso de votos disidentes es bastante limitado, ${ }^{40} \mathrm{y}$ la Corte, como tal, tiene primacía sobre sus miembros.

Retomando nuevamente la pregunta acerca de la manera en que las cortes constitucionales toman sus decisiones, los principales pasos de un protocolo útil en una investigación, pueden ser resumidos de la siguiente forma:

1) El mecanismo de acceso a la corte, examinado brevemente en la sección anterior. 2) La revisión/selección de casos (formal e informal). 3) Las reglas para asignar los casos entre los jueces. 4) El rol del greffe (el apoyo jurídico a la corte) y/o de los asistentes. 5) El procedimiento colectivo que conduce a la decisión (deliberación). 6) Y, como resultado: las decisiones de la corte, es decir, el texto autoritativo que dice el Derecho.

$* * *$

Voy a analizar diferentes protocolos o modos de producción de sentencias 24 constitucionales, comparando la corte plural paradigmática con las cortes colegiales europeas.

La Corte Suprema de Justicia de los Estados Unidos ${ }^{41}$

1. La apelación es enviada a la Corte por el litigante (usualmente quien ha perdido en la instancia) de un proceso que fue ventilado en una corte del

40 Künkler y State (2012) afirman que: «Entre 1971 (cuando se permitió la posibilidad de publicar disidencias) y 2012, solo el 7\% de las sentencias publicadas tenían algún voto disidente... Calculando sobre la base de un periodo de doce años, el número promedio de salvamentos de voto por juez es de 2.7» (p.21-22).

41 A este respecto es interesante el aporte de Greehouse (2012). 
circuito (que es una corte de apelación o de segunda instancia). ${ }^{42}$ Este litigante -o más probablemente su consejero o la American Civil Liberty Union-, espera obtener una revisión y revocatoria de la decisión judicial. Inmediatamente es posible notar que la Corte Suprema es un juez de jueces, y no sólo de la ley, como ocurre en algunas ocasiones cuando la Corte Alemana decide una queja constitucional, o Verfassungsbeschwerde.

2. La apelación es seleccionada o descartada por cuatro magistrados (al menos) en las reuniones que tienen lugar para el certiorari al comienzo del periodo judicial, y en las cuales se escogen los casos a ser decididos.

Vale la pena mencionar que en esta etapa temprana del procedimiento el rol de los asistentes (clerks) es crucial. Varios miles de apelaciones son recibidas cada año. Únicamente 100, o a veces menos, ${ }^{43}$ se seleccionan para ser decididas por la Corte Suprema. Los asistentes (cuatro, generalmente, por cada magistrado) leen todas las apelaciones y preparan un memo destinado a los magistrados por cada una de ellas. Sobre la base de estos memos los jueces seleccionan los casos para certiorari. Nótese que este mecanismo de filtración se justifica en el contexto del sistema norteamericano de judicial review, en el cual las cortes de instancia pueden decidir acerca de la constitucionalidad de la ley, de tal modo que si el caso no es revisado por la Corte, no hay «denegación de justicia». ${ }^{4}$

3. La Corte establece una agenda para escuchar los argumentos orales, vale decir, la discusión basada en el sistema adversarial entre las partes (i.e. sus abogados), y los magistrados (los nueve miembros de la Corte Suprema). Durante la audiencia los jueces formulan preguntas y establecen una conversación con los abogados. Estas audiencias permiten a las partes y al público tener una idea de lo que algunos jueces piensan individualmente con respecto al caso. Debido a las reglas y al procedimiento de decisión colectiva los magistrados norteamericanos tienen una personalidad pública, y el público puede formarse opiniones y expectativas alrededor de sus inclinaciones. Como es bien conocido hay magistrados conservadores, liberales y moderados en cada Corte Suprema

\footnotetext{
42 En cierto sentido la Corte estadounidense es comparable con la Cour de Cassation francesa. Este punto ha sido desarrollado por Lasser (2004).

43 En el 2015 la Corte decidió 69 casos. El número de peticiones recibidas por año ha llegado recientemente a 7000 .

44 En caso de que el control judicial sea concentrado y monopolizado por una única corte, este sistema de selección no es posible al menos explícitamente, o por errores materiales. En este sistema de control, como ya veremos, el modo de filtrar las peticiones debe ser diferente.
} 
en la historia de Estados Unidos. Esto ocurre en gran parte como resultado del mecanismo de elección explícitamente partidista.

4. Después de los argumentos orales los jueces se reúnen en sesiones privadas (llamadas conferencias) por unas pocas horas durante los miércoles y viernes en la tarde. Allí votan sobre la resolución del caso: confirmar, revocar (o dejar vacante), o remitir a la instancia (este punto es nuevamente similar a la Corte de Casación francesa).

5. Luego de que esta votación ha tenido lugar comienza una suerte de deliberación. Los argumentos son intercambiados esencialmente en forma escrita. De este modo no existe una deliberación «cara a cara» respecto de las razones contenidas en la sentencia, sino sólo algunos intercambios escritos sobre el borrador preparado por el magistrado a cuyo cargo está la redacción de la opinión mayoritaria. Es importante resaltar que el magistrado que debe escribir la opinión mayoritaria es seleccionado por un magistrado senior, en caso de que el Presidente de la Corte hubiese respaldado la opinión minoritaria frente a la parte resolutiva de la sentencia. Dado que esta asignación es importante, el Presidente de la Corte puede votar estratégicamente sobre el «resuelve» de la decisión para poder asignar el caso, por ejemplo, a sí mismo. Esto lo hizo el Presidente John Roberts en el caso de la denominada sentencia del «Obamacare». ${ }^{45}$

6. Los magistrados que fueron derrotados en relación con la parte resolutiva de la sentencia usualmente presentan una o más opiniones disidentes. Incluso en este caso, el intercambio de argumentos opera por escrito.

7. Los miembros de la mayoría que lograron un consenso sobre la parte resolutiva de la sentencia pueden presentar opiniones concurrentes en las cuales:

26 (a) esgrimen argumentos alternativos en relación con aquellos presentados por el magistrado a cargo de redactar la decisión; o (b) afirman su acuerdo parcial con las razones que soportan el «resuelve» del caso.

8. Finalmente, es posible que aunque exista consenso frente a la parte resolutiva de la sentencia, los argumentos ofrecidos no cuenten con el respaldo coherente de una mayoría definida. Esta situación puede producirse en aquellos casos en los que existe un gran número de opiniones concurrentes o disidentes, que pueden además ser parciales. En esta hipótesis la Corte decide el caso pero su sentencia no representa un precedente. Esta es la razón por la cual el

45 National Federation of Independent Business v. Sebelius, 567 U.S. - (2012), 183 L. Ed. 2d 450, 132 S.Ct. 2566. 
juez que escribe el borrador por la mayoría debe hacer un esfuerzo para reunir las opiniones jurídicas de los miembros de dicha mayoría alrededor de su razonamiento, para lo cual el juez puede agregar algunas enmiendas o integrar objeciones. Incluso es posible, aunque no usual, que la mayoría que apoyó la parte resolutiva no sobreviva el proceso de intercambio de borradores, sin contar con las aclaraciones o salvamentos de voto. ${ }^{46}$

Se debe prestar especial atención al hecho de que el valor de precedente de una decisión judicial es el objetivo más importante de la Corte Suprema. Esto porque las opiniones de Cortes Supremas o Constitucionales deben ser leídas como secuencias y no como actos aislados.

Parece plausible -ésta es, en cualquier evento, mi tesis-caracterizar este conjunto de pasos como un protocolo por el cual la masiva presencia de opiniones disidentes y concurrentes, así como el rol limitado de las deliberaciones «cara a cara», califica a esta corte no exactamente como un cuerpo colegial -el cual entiendo como la existencia de una sola voz por la cual la corte debe pronunciarse, como en la tradición jurídica clásica francesa- sino más bien como una corte plural, propia de las instituciones judiciales inglesas, cuyas decisiones se profieren en seriatim. ${ }^{47}$

\section{El Consejo Constitucional en Francia}

Si analizamos el Conseil Constitutionnel francés es posible notar que el tipo de protocolo que éste utiliza es profundamente diferente en comparación con la Corte estadounidense. Después de la reforma constitucional de 2010 es necesario distinguir entre el saisine parlementaire (desde 1974 el mecanismo clásico de remisión por el cual al menos 60 miembros de una de las dos Cámaras solicitan la revisión de una ley aprobada por el Parlamento antes de su promulgación) y la QPC (question prioritaire de constitutionalité: la versión francesa del konkrete Normenkontrolle alemán y de la eccezione di incostituzionalità italiana). El origen del problema que el Consejo debe decidir, los actores habilitados para remitir

46 Algunos aspectos paradójicos del proceso decisional de la Corte Suprema pueden verse en Kornhauser (2015).

47 De acuerdo con el Black's Law Dictionary el término en latín significa «uno después de otro». Una decisión seriatim es aquella «opinión proferida por una corte compuesta por varios jueces, en la cual cada juez lee su propia opinión, en lugar de contar con una sola decisión escrita por un juez en representación de toda la corte» (Wikipedia). Una mejor definición puede verse en Kornhauser (2015). 
el caso, el tiempo asignado para tomar las decisiones, e incluso algunos otros elementos del proceso decisional, no son esencialmente los mismos. Voy a examinarlos brevemente.

Primero, es importante subrayar el hecho de que a pesar de su nombre (Conseil), el órgano francés a cargo de la adjudicación constitucional es el epítome de una corte colegial que habla con una sola voz, como fue tempranamente establecido en las muy importantes ordonnances royales de Francisco I y Luis XIV. ${ }^{48}$

A continuación presento el camino decisional en los dos casos (saisine parlementaire y QPC). Primero los elementos comunes:

A) A diferencia de la Corte estadounidense, el Consejo Constitucional no puede seleccionar los casos. De hecho, debe decidir todas las questions ${ }^{49}$ de constitucionalidad que recibe: 92 en 2014, 87 en 2015, de las cuales la mayoría son QPC. Se debe tener en cuenta que la mitad de las cuestiones enviadas por los jueces a quo son «filtradas»-rechazadas- por la Corte de Casación y el Conseil d'Etat, y nunca llegan al Consejo Constitucional. ${ }^{50}$

B) El Presidente del Consejo tiene discrecionalidad para asignar las cuestiones de constitucionalidad a uno de los miembros de su institución. Este juez se denomina el juge rapporteur y juega (o más precisamente puede jugar) un rol relevante en la solución de la cuestión siempre que sea competente en su labor. ${ }^{51}$ Sin embargo, la mayoría de los borradores de las decisiones son preparadas por los abogados del service juridique. ${ }^{52}$ El nombre del juge rapporteur no es conocido

48 Sobre el origen del procedimiento de las cortes colegiales francesas ver Pasquino (2009).

49 El Consejo Constitucional, a diferencia de la Corte Suprema de los Estados Unidos, o de una Corte de Casación, no tiene que decidir disputas jurídicas tradicionales, sino responder questions formuladas por actores políticos o por litigantes en relación con la constitucionalidad de una ley que la mayoría parlamentaria ha aprobado, pero que el Presidente de la República no ha promulgado (saisine parlementaire), o que el juez de instancia debe aplicar con el fin de resolver el conflicto (QPC).

50 En un sentido se podría decir que la adjudicación constitucional en Francia no es monopolio de un único órgano sino que, al menos, ésta se distribuye negativamente: las Altas Cortes tienen la llave para abrir la puerta del Consejo Constitucional.

51 No hay ningún requisito de experiencia jurídica previa para ser elegido en el Consejo Constitucional. Sociólogos y políticos han hecho parte de esta institución. Ésta es una diferencia muy importante vis-à-vis las otras cortes constitucionales y que tiene su razón de ser en los orígenes del Consejo.

52 Está compuesto por el Secretario General (usualmente un miembro del Conseil d'Etat) y, ahora, por cuatro expertos en Derecho altamente calificados. Esta secretaría tiene un papel fundamental en la elaboración de las decisiones del Consejo: prepara borradores de todas las cuestiones enviadas, y discute cada uno de ellos con el juge rapporteur, quien no necesariamente es un experto en derecho constitucional. Los miembros del Consejo, a diferencia de los magistrados de las Cortes 
por el público, puesto que las decisiones del Consejo son todas ellas per curiam, es decir, decisiones de la Corte: colegiales y anónimas.

No obstante, el procedimiento sigue caminos ligeramente diferentes en el procedimiento decisional, dependiendo del actor que se encuentre al comienzo del proceso judicial. En cuanto al saisine parlementaire -la cuestión se envía antes de la promulgación de la ley por los senadores o los miembros de la Assemblée Nationale ${ }^{53}$ - el Presidente del Conseil Constitutionnel es normalmente informado por el líder de la oposición parlamentaria que tiene la intención de remitir la ley, una vez ésta sea aprobada por el Parlamento. De este modo, el Presidente tiene la posibilidad de seleccionar un rapporteur in pectore, quien seguirá los debates parlamentarios y estará listo para preparar, junto con el service juridique, el reporte preliminar que debe presentar para la deliberación del Consejo.

La razón subyacente a este prima facie inusual procedimiento es perfectamente entendible si se tiene en cuenta que las leyes francesas a ser escrutadas pueden ser largas y complejas, y que el Consejo tiene únicamente un mes para producir la decisión desde el día de la remisión.

Debemos pensar que el borrador de la decisión será discutido en la conferencia (la délibéré), la cual usualmente tiene lugar uno o dos días antes del término final para la publicación de la sentencia. Esta limitación imperativa de tiempo tiene un impacto relevante sobre el proceso deliberativo. Cuando la deliberación «cara a cara» comienza, hay muy pocas horas para alcanzar una decisión final. Bajo la severidad de estas condiciones (mínimas) deliberativas, el juge rapporteur no puede correr el riesgo de entrar a la discusión del Consejo sin la cuasi-certidumbre de que al menos la mitad de los miembros están de acuerdo con su borrador básico. Un serio desacuerdo entre los integrantes del cuerpo colegial produciría un bloqueo, algo que debe ser evitado a toda costa. ¿Qué puede hacer el juge rapporteur en este tipo de situaciones? En primer lugar, debe solicitar la ayuda de la oficina judicial del Consejo. Como ya se dijo, el borrador de la decisión es preparado, generalmente, por la oficina judicial y discutido con el juge rapporteur antes del comienzo de la deliberación. Además, puede ver a

Constitucionales de Alemania, Italia, y España no tienen asistentes personales (clerks). El service juridique trabaja para el Consejo, y sus miembros dependen en cierta medida de aquél. Un texto anónimo que explica el role del service juridique puede leerse en el siguiente enlace: http://www. conseil-constitutionnel.fr/conseil-constitutionnel/root/bank_mm/pdf/Conseil/20050930.pdf 53 Aunque rara vez ocurre, otros cuatro actores políticos pueden remitir casos: el Presidente de la República, el Primer Ministro, y los Presidentes de las dos cámaras del Parlamento. 
sus colegas antes de la deliberación y mantener conversaciones informales con ellos: los miembros del Conseil Constitutionnel tienen sus oficinas ubicadas en el mismo corredor del pequeño edificio del Consejo, justo al lado de la sede del Conseil d'Etat, en el Palais Royal. Así que antes de las cortas deliberaciones que ponen fin al proceso decisional, el juge rapporteur puede discutir con sus colegas, y buscar el consenso necesario para lograr la decisión. Puede agregarse que en ausencia de un proceso adversarial, el juge rapporteur -algunas veces en presencia de algunos de sus colegas si ellos lo desean-puede discutir la cuestión de constitucionalidad con los representantes del gobierno, o intercambiar argumentos por escrito con las partes del conflicto constitucional. ${ }^{54}$

Éstas son algunas de las partes invisibles o sumergidas del iceberg que llamaremos en corto «deliberación», en tanto que la única parte que se puede percibir es la decisión publicada y sus argumentos, los llamados considérants.

Es relevante poner de presente que las opiniones relativamente cortas y mayormente crípticas del Consejo Constitucional son publicadas desde hace algunos años, en su excelente página web, con un comentario escrito por el service juridique. Ocasionalmente este análisis puede ser más largo que la misma opinión, y es mucho más fácil de entender para los no especialistas. ${ }^{55}$

Enfoquémonos ahora en la QPC cuyo protocolo decisional es un tanto diferente. En este caso hay argumentos orales adversariales, más bien cortos y sin contrainterrogatorio, ${ }^{56}$ entre el demandante (él mismo o su abogado) y el abogado del gobierno, quienes presentarán dos interpretaciones diferentes de la Constitución. Luego de este paso el procedimiento es igual al descrito para el saisine parlementaire, aunque en el caso de la QPC la Corte tiene un periodo mayor para decidir (tres meses).

Otra diferencia merece ser considerada. En el saisine parlementaire la ley es objeto de un escrutinio ex ante, esto es, antes de su promulgación; lo cual, hasta

54 Estoy agradecido con Olivier Dutheillet de Lamothe, juez emérito del Consejo Constitucional por estos detalles.

55 Ver, por ejemplo, la denominada opinión de la «burka», que sólo tiene una página (http://www. conseil-constitutionnel.fr/conseil-constitutionnel/francais/les-decisions/acces-par-date/decisionsdepuis-1959/2010/2010-613-dc/decision-n-2010-613-dc-du-7-octobre-2010.49711.html), mientras que su comentario tiene seis (http://www.conseil-constitutionnel.fr/conseil-constitutionnel/root/ bank/download/2010613DCccc_613dc.pdf).

56 Siendo la opinión de la Corte per curiam y anónima, es posible entender por qué durante los argumentos orales (en Francia y en Italia) los jueces no manifiestan sus opiniones y, en general, se abstienen de preguntar a los abogados de las partes. 
2010, mantenía viva la ideología que pretendía afirmar que la ley es la expresión de la voluntad general, lo que a su turno es una forma francesa de decir que la ley es correcta y, por la misma razón, es compatible con la constitución. El control, en este caso, es además abstracto, en el sentido de que el escrutinio por el Consejo se refiere a una ley independientemente de su aplicación en un caso concreto. En realidad, el Consejo ha tratado de anticipar los efectos de la ley en su aplicación concreta porque, en términos generales, es poco probable que ésta sea abiertamente contraria a la Constitución. ${ }^{57}$

En el caso de la QPC, el control es ejercido ex post porque se refiere a leyes promulgadas. La Corte colegial tiene, por tanto, la posibilidad de observar de manera detallada los efectos de la ejecución de la ley, y de considerar sus consecuencias concretas, las cuales pueden haber sido imprevisibles para los representantes elegidos cuando ejercieron su poder legislativo bajo una suerte de velo de la ignorancia en relación con las aplicaciones específicas de la ley. El carácter de generalidad de la ley (Locke) hace inevitable este aspecto de la legislación parlamentaria, que la Corte puede corregir mediante su escrutinio.

\section{La Corte Costituzionale italiana}

Este Tribunal sigue, la más de las veces, un protocolo similar al examinado con la QPC en Francia. No obstante, es importante resaltar los elementos procedimentales comunes y detallar algunas diferencias cruciales.

\section{Aspectos comunes:}

1. El presidente de la Corte Italiana, elegido por sus miembros típicamente por un corto periodo de tiempo, y a diferencia de Francia, sin la intervención del Presidente de la República, asigna las cuestiones a un juge rapporteur. ${ }^{58}$

2. En cerca del $20 \%$ de los casos hay un procedimiento adversarial que es costoso porque se debe pagar a los abogados, pero innecesario para el éxito del demandante. En este escenario procesal los magistrados no hacen visible su opinión.

57 Guy Canivet, primer presidente de la Cour de Cassation y miembro del Consejo Constitucional me puso al tanto de esta realidad.

58 Ésta es una facultad discrecional, pero el Presidente considera, al asignar los expedientes, la experiencia específica de los miembros individuales de la Corte. 
3. La corte siempre decide per curiam: una voz. Sin embargo, el nombre del juge rapporteur (quien redacta la opinión de la Corte) ${ }^{59}$ es divulgado. De manera similar al Conseil la publicación de opiniones disidentes o concurrentes está prohibida. ${ }^{60}$

\section{Las diferencias recaen en tres aspectos:}

1. El número de casos de la Corte italiana ha sido tradicionalmente mucho más importante que en la experiencia francesa. ${ }^{61}$ Los jueces, aún siendo expertos en Derecho, ${ }^{62}$ no podrían administrar ellos mismos el trabajo necesario para producir tal número de decisiones sin la ayuda sustantiva de sus asistentes. En Italia, a diferencia del Consejo Constitucional francés, cada magistrado de la Corte tiene tres auxiliares, que éste escoge libremente entre jueces jóvenes y académicos, quienes le ayudan a preparar el borrador de la opinión, y quienes notablemente se basan en casos decididos previamente por la misma Corte y por otros tribunales constitucionales de estados democráticos. El papel de los asistentes y/o de los servicios judiciales en las altas cortes es definitivamente un asunto que merece más investigación que la que se ha desarrollado hasta ahora. ${ }^{63}$

2. La ausencia de limitantes temporales para proferir las decisiones, con excepción de la admisibilidad de referendos que derogan leyes aprobadas por

59 De hecho, en el texto de las sentencias de la Corte italiana dos expresiones se usan de manera intercambiable: el juez relatore y el juez redattore. El primero presenta la cuestión de constitucionalidad a sus colegas al comienzo de la deliberación, mientras que el último escribe la opinión de la Corte. En general, las dos figuras recaen en la misma persona. Excepcionalmente (una o dos veces al año) el nombre del redattore difiere del nombre del relatore. Ésta es una señal de que éste no pudo persuadir a la Corte y, aún más, no está convencido de los resultados de la deliberación colectiva. En este escenario el relatore le pide al Presidente que designe otro juez para que redacte la opinión. Esta resistencia no es, aparentemente, posible en la Corte alemana. 60 Como en otras altas cortes europeas: Austria, Bélgica, y el Tribunal de Justicia de la Unión Europea en Luxemburgo.

61 De 592 en el año 2000 a 276 en 2015. Las estadísticas pueden consultarse en: http://www. cortecostituzionale.it/documenti/interventi_presidente/Dati_2015.pdf

62 Artículo 135 de la constitución italiana: «Los magistrados del Tribunal constitucional serán escogidos entre los magistrados, incluso los jubilados, de las jurisdicciones superiores ordinaria y administrativas, los profesores catedráticos de Universidad en disciplinas jurídicas y los abogados con más de veinte años de ejercicio profesional».

63 En cuanto a los auxiliares de la Corte Constitucional italiana ver: Lamarque, E. (2011, p.10661085). De manera más general: The Role of Assistants-Magistrates in the Jurisdiction of Constitutional Courts, Universul Juridic, Bucarest, 2016. 
el parlamento, ${ }^{64}$ implica que la deliberación «cara a cara» en la Corte italiana está mucho más desarrollada, particularmente en todos los casos difíciles e importantes. ${ }^{65}$ En un texto que se puede consultar en su página web, la Corte ha descrito claramente el procedimiento formal e informal para arribar a una decisión. ${ }^{66}$ Éste busca, principalmente, una decisión consensuada entre los miembros de la Corte como órgano colegiado. La ausencia de salvamentos y aclaraciones de voto -siguiendo la tradición francesa de una corte que habla con una sola voz- representa un incentivo para encontrar una postura intermedia entre las posiciones divergentes en aquellos casos de desacuerdo entre los magistrados. La ausencia de limitantes temporales para decidir permite la posibilidad de deliberar para lograr un acuerdo, ${ }^{67}$ teniendo en cuenta que el mismo problema puede ser discutido en más de una reunión, lo cual es habitual para cualquier decisión importante.

3. En cuanto al tipo de remisiones, es más fácil abrir la puerta de la Corte italiana que la de su contraparte francesa. Desde que la Corte Constitucional inició sus actividades (1956) estaban permitidas tanto la remisión por parte de jueces ordinarios como aquellas relativas a los conflictos de competencias de altos órganos del estado. Con la progresiva devolución de funciones legislativas a las regiones surgieron conflictos entre el legislador nacional y las legislaturas locales. En consecuencia, la Corte comenzó a ejercer una función similar a la de un juez federal. Esta función se volvería la más importante en los últimos años, debido a una reforma constitucional aprobada en 2001 que expandió las competencias legislativas de las regiones de una forma poco clara. ${ }^{68}$ Por otro lado no existe un filtro entre los jueces ordinarios y la Corte Constitucional, a

64 La ley constitucional del 11 de marzo de 1953 (n. 2), estableció la competencia para revisar la admisibilidad de los referendos del artículo 75 de la Constitución.

65 Siguiendo a Favoreu, profesor de derecho constitucional francés, es conveniente distinguir entre micro y marco-constitucionalidad. Sólo el segundo tipo de decisiones (que tienen un impacto más significativo sobre el sistema político-jurídico) es objeto de una deliberación prolongada, en búsqueda de una decisión ampliamente compartida. En cuanto a los casos simples, el borrador preparado por el rapporteur puede ser fácilmente aceptado por sus colegas, con pequeñas enmiendas si es necesario.

66 http://www.cortecostituzionale.it/documenti/download/pdf/Cc_Checosa_2013_UK.pdf Ver particularmente la sección 6: ¿Cómo opera la Corte?, p. 50-51. El juez Valerio Onida es el autor del texto, que fue posteriormente revisado por el juez Stefano Silvestri.

67 Sobre esta perspectiva es importante el aporte de Zagrebelsky (2008), quien fuera presidente de la Corte Constitucional Italiana.

68 Ver: Caravita, Nápoles, Jovene, (2012). 
diferencia de Francia con la QPC; y, adicionalmente, no existe en el sistema constitucional italiano una figura equivalente al saisine parlementaire. ${ }^{69}$

\section{La Corte Constitucional alemana, Bundesverfassungsgericht}

El modo de trabajo de la Corte Constitucional Federal depende en gran medida del gran número de casos que conoce. Como ya se mencionó, el alto número de quejas constitucionales individuales (Verfassungsbeschwerden) ${ }^{70}$ impone no solamente una estricta división del trabajo entre sus magistrados, ${ }^{71}$ sino también la fundamental cooperación de los servicios administrativos de la Corte (Registar), y de los asistentes de los magistrados (cuatro por cada juez). ${ }^{72}$ Las quejas constitucionales normalmente no se discuten «cara a cara» en las cámaras (compuestas por tres magistrados). Cuando una queja es recibida en la Corte, el juez rapporteur decide si ésta debería ser decidida en la cámara (Kammer), o en el panel (el Senat) que está compuesto por ocho jueces. Por regla general es la cámara quien decide, mientras que la resolución del caso en el panel es la excepción. En la primera hipótesis (decisión en la cámara) un magistrado (o sus asistentes) elaboran un memo corto, y un borrador con la opinión (Votum). Estos documentos circulan entre los otros dos miembros de la cámara, quienes usualmente se adhieren a la decisión proyectada. En algunos eventos un miembro de la cámara puede sugerir cambios en la redacción; y, una vez estos se han hecho, el memo y el borrador circulan una vez más entre los integrantes de la cámara. En muy pocas ocasiones (aproximadamente 10 cada año) los miembros de la cámara solicitan una discusión. En caso de que alguno

69 Después de la promulgación de normas regionales, el gobierno central puede, en aquellos casos en los cuales considera que estas reglas locales no son compatibles con la constitución, enviarlas inmediatamente para su análisis por parte de la Corte.

70 Aproximadamente 10.000 en años recientes, de las cuales el 60\% son decididas por la Corte, mientras que el $40 \%$ restante son simplemente rechazadas por el Register por cuenta de errores materiales, como por ejemplo, la remisión de la queja después de un largo periodo de tiempo. Las estadísticas sobre las remisiones y las decisiones en 2015 están disponibles en la página web del Tribunal Federal: http://www.bundesverfassungsgericht.de/SharedDocs/Downloads/EN/Statistik/ statistics_2015.pdf?_blob= publicationFile \&v $=3$

71 Esta distribución se establece cada año por la Corte y por los Presidentes de sus dos paneles (Senaten) quienes, además de decidir casos, no tienen discrecionalidad para asignar casos a los demás magistrados.

72 En relación con los auxiliares de los magistrados de la Corte alemana, véase a Scheffczyk . El modo de trabajo detallado de la Corte puede encontrarse en la Bundesverfassungsgerichtsgezetz (ley del Tribunal Constitucional Federal Alemán). 
de los otros dos magistrados no concuerde con la decisión propuesta, el caso es remitido al panel (Senat). ${ }^{73}$

Los asistentes de los magistrados desempeñan un papel crucial en este proceso, en tanto que examinan la mayoría de las quejas constitucionales y preparan los memos. ${ }^{74}$ Por su parte, una queja es rechazada si los tres magistrados de la cámara así lo deciden de forma unánime, y en este caso el Votum, con los argumentos y las referencias a precedentes y doctrina, no se publica sino que se traslada a los archivos de la Corte. ${ }^{75}$

Por otra parte, como ya se advirtió, en casos muy específicos el expediente es remitido a uno de los Senados para su decisión. Los dos Senados que componen la Corte, cada uno con ocho miembros de los cuales la mayoría han sido jueces o profesores de Derecho, ${ }^{76}$ son el escenario decisional de todas las cuestiones constitucionales relevantes. Los cincuenta casos que los dos Senados deciden anualmente son objeto de una seria deliberación entre los ocho miembros de cada panel. ${ }^{77}$ El proceso de deliberación es, a grandes rasgos, el mismo que se utiliza para cuestiones macro-constitucionales en la Corte Constitucional italiana. Para anular la ley se requiere el consenso de cinco de los ocho jueces. ${ }^{78}$ Además, como la Magistrada emérita de la Corte Constitucional alemana Gertrude Lübbe-Wolff escribió en un texto reciente:

Se dice que el que el Juez debe ser elegido con dos tercios de mayoría (del Bundestag y el Bundesrat). Éste es un aspecto que mantiene alejadas de la Corte a aquellas personas con un alto potencial de polarización y, contribuye de igual forma, a lograr acuerdos no sólo al momento de la elección parlamentaria, sino también con sus compañeros magistrados una vez se es elegido ${ }^{79}$ (Lübbe-Wolff, 2015, p.31).

73 Le debo todos estos detalles al Profesor Dieter Grimm.

74 Depende del magistrado correspondiente saber si sus auxiliares deben o no revisar todas las quejas individuales y preparar memos para cada una de ellas.

75 En mi visita a Karlsruhe fui informado que la razón por la cual los memos no son publicados, radica en que los auxiliares no tienen tiempo suficiente para preparar una opinión perfectamente elaborada (desde el punto de vista formal) para su divulgación.

76 Éste no ha sido siempre el caso, pero ahora la presencia de académicos es destacada. Ver: Moes (2016).

77 Sobre la estructura del Tribunal Constitucional Federal Alemán y las competencias correspondientes a los dos Senados ver: Farahat.

78 En caso de empate (4 a 4) el estatuto no se anula.

79 Ver Lübbe-Wolff (2015, p.31). 
La deliberación de la Corte tiene como función -y es proclive a- lograr un acuerdo entre los magistrados, lo cual explica el número tan limitado de disidencias (Sondervotum). De hecho, como ha agregado Lübbe-Wolff (2015):

En el contexto de una cultura de deliberación generalmente orientada hacia el consenso, justamente también se genera la posibilidad de articular acuerdos que, adicionalmente, tengan la capacidad de incentivar dichos consensos. Esto también contribuye de una manera fundamental a que las objeciones, las propuestas y los argumentos sean tomados seriamente y a que se genere un esfuerzo deferente para lograr un acuerdo con aquellos que las presentan (p.31-32). ${ }^{80}$

La costumbre deliberativa/consensual de la mayoría de las cortes constitucionales europeas es, ciertamente, un elemento que explica su reputación como órganos super partes y su credibilidad ante la opinión pública. ${ }^{81}$

\section{3.}

Los protocolos decisionales de las tres Cortes europeas analizadas anteriormente representan los modelos de la mayoría de los tribunales europeos más recientemente creados que están a cargo de la adjudicación constitucional, particularmente aquellos establecidos en regímenes post-autoritarios en Europa del Sur y en Europa Oriental, después de la caída de los regímenes fascistas y soviéticos. La influencia más fuerte provino del Tribunal Constitucional alemán, que es la Corte más antigua y prestigiosa del viejo continente, con la excepción del Verfassungsgericht austríaco, establecido en 1920 en gran parte gracias a Kelsen, pero desmantelado por los enemigos de la democracia constitucional.

Varias lecciones pueden extraerse de este panorama rápido y parcial sobre las formas y modalidades para tomar decisiones en las cortes constitucionales, y que están relacionadas con las diversas vías de remisión de casos a las cortes. La adjudicación constitucional es uno de los mecanismos que contribuye a crear una

80 Lübbe-Wolff (2015, p. 31-32) Traducción libre. Sobre la deliberación interna del Tribunal y cómo sus jueces toman sus decisiones, es muy útil ver a Grimm, D (2016).

81 Según Lübbe-Wolff (2015, p. 38): «De conformidad con la encuesta de 2014 publicada por el Instituto para la opinión pública de Allensbach, el 79\% de los ciudadanos tenían una gran confianza en el Tribunal Constitucional Alemán» (p.38). Traducción libre. Algunos datos semejantes sobre la Corte Italiana y el Consejo Francés pueden verse en: http://www.eurispes.eu/content/la-fiduciadei-cittadini-nelle-istituzioni-rapporto-italia-2013 y en http://www.cevipof.com/fr/le-barometrede-la-confiance-politique-du-cevipof/resultats-1/vague6/vague6bis/ respectivamente. En el caso francés, los datos se refieren a la rama judicial en general. 
democracia limitada. ${ }^{82}$ Ante la ausencia de controles derivados de mecanismos democráticos/electorales, las Cortes Constitucionales deben exhibir ciertas cualidades: independencia y neutralidad. Por el contrario, estas características no son necesarias (o posibles) para actores políticos elegidos, o para sus mayorías, puesto que estos últimos son controlables por su electorado, y no por el público en general. Por independencia quiero significar simplemente que los jueces constitucionales, al no ser controlables por el gobierno o los ciudadanos (su periodo no es renovable como ocurre en la mayoría de los casos), deben contar con la precondición esencial de la neutralidad: los magistrados no dependen de los intereses de las partes involucradas en los conflictos constitucionales que deben resolver. Por la expresión «neutralidad» no quiero señalar que debe existir objetividad absolutamente perfecta (esta definición únicamente encajaría en la versión teológica del concepto), sino, más bien, hago referencia a la calidad de las decisiones que son el resultado del compromiso de preferencias diferentes y balanceadas. Esto sólo puede lograrse, al menos de forma aproximada, bajo ciertas condiciones relativas a la elección de los miembros de las cortes, así como al protocolo que se usa para decidir:

1. No deben existir periodos vitalicios o excesivamente largos.

2. No deben existir elecciones partidistas. Eso supone el acuerdo de la oposición como ocurre en Alemania.

3. No deben existir restricciones temporales para la deliberación, contrario a lo que ocurre en Francia.

4. Se deben asignar suficientes asistentes a los magistrados para evitar que estos últimos sean menos importantes que (y dependientes de) la oficina de servicios jurídicos de la Corte (como puede ser el caso del Consejo Constitucional francés).

5. Se debe evitar la personalización de los miembros de la Corte por cuenta del exceso de votos disidentes.

Paso a desarrollar cada una de estas ideas:

1. Un periodo vitalicio para los magistrados de las cortes constitucionales tenía sentido en el siglo XVIII (justamente cuando fue redactada la Constitución 
estadounidense) cuando la expectativa de vida era inferior a los cincuenta años. En el siglo XXI los miembros de cortes cuyo periodo es vitalicio pueden servir por más de 20 años $^{83}$ gracias al progreso de la medicina y de las condiciones de vida en general. Esto parece ser incompatible con una cultura republicana en la cual las elecciones de los actores a cargo de crear Derecho suponen mandatos pro tempore, renovables únicamente mediante elecciones. Además, las elecciones de los integrantes de una corte bajo esas condiciones se vuelven desmesuradamente importantes, y crean un escenario propicio para la selección de magistrados excesivamente jóvenes y con intereses partidistas, como hemos visto cada vez más y más en las recientes elecciones de la Corte norteamericana. Una elección vitalicia otorga mucho poder a los miembros de la Corte e impide la necesaria rotación en este tipo de instituciones.

2. La elección de los magistrados de la corte debería hacerse, además, siguiendo algunas reglas que minimicen los intereses partidistas del juez. El mecanismo usado en Alemania, donde se requiere el apoyo de la oposición parlamentaria, es una garantía importante. En los Estados Unidos, cuando no hay "gobierno dividido», ${ }^{84}$ el partido que controla tanto el Senado como la Casa Blanca puede elegir cualquier juez radical, siempre que éste sea un experto jurídico competente.

En tanto que los intereses partidistas del juez son usualmente calificados como políticos, una observación general puede ser apropiada. Se dice, incluso en forma crítica, que las Cortes Constitucionales no toman decisiones jurídicas sino políticas; aunque no es totalmente claro qué significa la palabra «políticas» en este contexto. Una reflexión muy interesante sobre esta crítica fue presentada en 1938 por Richard Thoma (profesor de Heidelberg) en la conferencia de

83 La mayoría de los magistrados de la Corte Suprema de Justicia de los Estados Unidos que fueron elegidos después de 1950 sirvieron alrededor de 20 años: Brennan 33, White 31, Stevens 34, y Scalia 30. Kennedy, Thomas, Roberts, Alito, Sotomayor, Kagan, y el reemplazante de Scalia podrían permanecer más. Los largos periodos de algunos de los más importantes líderes europeos (aún con reelección) como Adenauer, Schmidt, Mitterrand, Thatcher o Merkel no se comparan con los de dichos magistrados. En el Tribunal Constitucional Federal de Alemania no muchos jueces permanecen en la magistratura por el periodo total de 12 años, debido a la edad de retiro forzoso (72 años). En Austria los miembros del Tribunal Constitucional pueden servir hasta la edad de 70 años, aunque $\mathrm{K}$. Korinek fue miembro de la corte durante 30 años.

84 En caso de que exista «gobierno dividido", el candidato nominado por el Presidente debe contar con el aval de un Senado cuyas mayorías responden a un color político distinto. Por ejemplo Robert Bork, el candidato del Presidente Reagan, no pudo obtener la aprobación del Senado controlado por los demócratas. Esta situación auspició la elección del más moderado Anthony Kennedy en 1988. 
profesores de Derecho Público de habla alemana en Viena, cuando discutió las contribuciones presentadas por $\mathrm{H}$. Triepel y H. Kelsen. Su argumento puede ser resumido y parafraseado de la siguiente forma:

a. En un sentido más general y débil, cualquier decisión de una Corte Constitucional puede ser catalogada como política, dado que tiene un impacto sobre un número (menor o mayor) de ciudadanos, quienes son miembros de la comunidad política (polis). Esto es así incluso si la decisión de la Corte supone una interpretación relativamente pacífica de la Constitución.

b. En muchos casos, y en un sentido diferente del término «político», es posible que los miembros de la Corte estén en desacuerdo entre sí, debido a juicios de valor diferentes y opuestos. Estos juicios pueden ser denominados políticos, en el sentido en que son subjetivos y no únicamente técnico-jurídicos. Thoma parece haber planteado que la interpretación constitucional depende de la opinión de los jueces, y que los posibles desacuerdos entre ellos evidencian que no hay una única respuesta a los dilemas acerca de la constitucionalidad de las leyes, independientemente de los prejuicios partidistas.

c. Finalmente, hay casos en los que las Cortes deben tomar decisiones para llenar los vacíos del texto constitucional, teniendo en cuenta que todas las constituciones son, inevitablemente, contratos incompletos. En estos escenarios, más que una interpretación de la constitución, deberíamos referirnos a una labor que complementa el texto constitucional. ${ }^{85}$

La presencia simultánea de diferentes inclinaciones políticas, así como de una sensibilidad tendiente a encontrar un «terreno intermedio» por medio de la deliberación, permitiría que las decisiones políticas de las Cortes respondan menos a intereses partidistas en comparación con las determinaciones que toma a una mayoría elegida en el Parlamento, como lo señala Lübbe-Wolff.

3. La deliberación «cara a cara» es una condición necesaria que le permite a la Corte alcanzar un compromiso entre las posturas de los magistrados. Si ésta no tiene lugar, o si se desarrolla en un periodo muy corto, como en el Consejo

85 Kelsen y Triepel (1965, p. 107-108). Ver también: Lieto y Pasquino (2015, p. 351-388); y

Zagrebelsky (2004). 
francés, la votación tomará el lugar de la deliberación, con lo cual la Corte se transformará en un micro-parlamento, donde los votos más que los argumentos son el criterio determinante para alcanzar la decisión final. ${ }^{86}$

4. Si una corte - una vez más, como la francesa- no le permite tener asistentes a sus magistrados, es posible que su dependencia de la oficina de servicios jurídicos aumente, con lo cual tanto el juge rapporteur como la oficina jurídica tendrán una posición privilegiada en relación con los demás jueces. Si los magistrados tienen sus propios asistentes, tendrán la posibilidad de considerar y/o seguir con más precisión las decisiones que debe tomar la corte, gracias al apoyo de sus auxiliares en todos los casos.

5. Por último, aunque no menos importante, los votos disidentes o concurrentes, donde actualmente se permiten, deberían ser anónimos, o usados muy limitadamente. Los méritos de esta antigua práctica decisional de las cortes inglesas son generalmente exagerados, pero no hay ninguna razón para oponerse de manera radical. Lo que resulta ser contrario al espíritu de una corte neutral es el abuso de las disidencias. Una tentación constante a la cual el juez se debe resistir radica en usar el salvamento para dirigirse a un público externo a la Corte, en lugar de entablar un diálogo con los colegas con quienes tomará la decisión. ${ }^{87}$ El uso excesivo de estos votos convierte a la Corte en un órgano partidista, en el cual cada uno de sus integrantes está más preocupado por defender su propia teoría de la interpretación, más que por una solución colectiva y consensuada de las cuestiones y casos que el tribunal debe decidir.

86 Sobre la diferencia entre votar y argumentar, véase el artículo citado en la nota al pie 39.

87 Véase a Ferejohn y Pasquino (2002, p.21-36). 


\section{Bibliografía}

Bryce, J. (1901). Flexible and rigid constitutions. Studies in History and Jurisprudence, 1, 145.

Cappelletti, M. (1984). Giudici legislatori? (Vol. 24). Giuffrè.

Caravita, B., Chiappetti, A., Chiola, C., D’Onofrio, F., Ridola, P., Rordorf, C. R., ... \& Basili, D. (2011). La giustizia costituzionale in trasformazione: la Corte costituzionale tra giudice dei diritti e giudice dei conflitti. Atti del Convegno di Roma, Facoltà di Scienze politiche, Sociologia, Comunicazione, 11.

Cassese, S. (2017) La democrazia e i suoi limiti, (en prensa)

De Santa Cruz Oliveira, M. A. (2006). Reforming the Brazilian Supreme Federal Court: A Comparative Approach. Wash. U. Global Stud. L. Rev., 5, 99.

Eisenmann, C. (1986). La justice constitutionnelle et la Haute Cour constitutionnelle d'Autriche. Economica.Jasper, G. (1963). Der Schutz der Republik: Studien zur staatlichen Sicherung der Demokratie in der Weimarer Republik, 1922. 1930 (No. 16). Mohr (P. Siebeck).

Elster, J. (Ed.). (2015). Secrecy and publicity in votes and debates. Cambridge University Press.

Farahat, A. "Das Bundesverfassungsgericht" en Jus Publicum Europeum, Bd. VI.

Ferejohn, J., \& Pasquino, P. (2002). Constitutional courts as deliberative institutions: towards an institutional theory of constitutional justice. LAW AND PHILOSOPHY LIBRARY, 21-36.

Greehouse, L. (2012) The U.S. Supreme Court, Oxford University Press.

Hamilton, A., \& Madison, J. (2001). John Jay, El Federalista.

Kelsen, H. (1928). Wesen und Entwicklung der Staatsgerichtsbarkeit. Gruyter.

Kelsen, H. (1942). "Judicial Review of Legislation: A Comparative Study of the Austrian and the American Constitution". The Journal of Politics, 4(2), pp. $183-200$

Kingston, R. (2013).Parlement/Parlements. http://dictionnaire-montesquieu.ens lyon.fr/en/article/1377636897/en/ 
Kornhauser, L. A. (2016). DECIDINDO JUNTOS. REI-REVISTA ESTUDOS INSTITUCIONAIS, 1(1), 38-61.

Künkler, M., \& Stein, T. (2016). State, Law, and Constitution: Ernst-Wolfgang Böckenförde's Political and Legal Thought in Context.

Lamarque, E. (2011). Chi sono gli assistenti di studio dei giudici costituzionali.

Lasser, M. (2004) Judicial Deliberations. A Comparative Analysis of Transparency and Legitimacy, Oxford University Press.

Lieto, S., \& Pasquino, P. (2015). Metamorfosi della giustizia costituzionale in Italia. Quaderni costituzionali, (2), 351-385.

Löwer, W., \& Landfried, C. (1986). Bundesverfassungsgericht und Gesetzgeber. Wirkungen der Verfassungsrechtsprechung auf parlamentarische Willensbildung und soziale Realität.

Lübbe-Wolff, G. (2015). Wie funktioniert das Bundesverfassungsgericht?. Universitätsverlag Osnabrück, V \& R Unipress.

Merkl, A. (1931). Prolegomena einer Theorie des rechtlichen Stufenbaues (pp. 252-294). Springer Vienna.

Mouton, S. (2016). Le régime représentatif à l'épreuve de le justice constitutionnelle, LGDJ.

Pasquino, P. (2009). New Constitutional Adjudication in France: The Reform of the Referral to the French Constitutional Council in Light of the Italian Model. INDIAN J. CONST. L., 3, 105-117.

Pasquino, P. (2012). Classifying Constitutions: Preliminary Conceptual Analysis. Cardozo L. Rev., 34, 999.

Pasquino, P. (2015). The New Separation of powers: Horizontal Accountability, Italian Journal of Public Law, Vol. 7, Issue 1, , p. 157-169.

Pasquino, P., \& Randazzo, B. (2006). Giustizia costituzionale ed i suoi utenti: atti del Convegno internazionale in onore del prof. Valerio Onida organizzato dalla Fondazione Adriano Olivetti e dalla Facoltà di giurisprudenza dell'Università degli studi di Milano: Milano, 15 aprile 2005. 
Pasquino, P., \& Randazzo, B. (Eds.). (2009). Come decidono le Corti Costituzionali (e altre Corti)-Atti del Convegno internazionale (Milano, 25-26 maggio 1977) (Vol. 65). Giuffrè Editore.

Patapan, H. (2000). Judging Democracy: the new politics of the High Court of Australia. Cambridge University Press.

Rakove, J. N. (1997). The Origins of Judicial Review: A Plea for New Contexts. Stanford Law Review, 1031-1064.

Reynolds, G. H., \& Denning, B. P. (2013). National Federation of Independent Business v. Sebelius: Five Takes.

Roy, J. P. (2005). Bruno Latour, La fabrique du droit, une ethnographie du Conseil d'État. Paris, Éd. La Découverte, Poche, coll. Sciences humaines et sociales, 2004, 320 p. Questions de communication, (8), 508-510.

Scheffczyk, F. "The Role of the Judicial Clerk at the German Federal Constitutional Court", in The Role of assistant-Magistrates, citado en la nota al pie 65 , p. 74-78.

Smend, R. (1911). Das Reichskammergericht. H. Böhlau.

Stone, A., \& Sweet, A. S. (1992). The birth of judicial politics in France: The Constitutional Council in comparative perspective. Oxford University Press on Demand.

Triepel, H. (1929). Wesen und Entwicklung der Staatsgerichtsbarkeit (Vol. 5). Walter de Gruyter.

Wehler, W. (1979). Der Staatsgerichtshof für das Deutsche Reich. Die politische Rolle der Verfassungsgerichtsbarkeit in der Zeit der Weimarer Republik.-Bonn 1979. XXXVII, 396 S. $8^{\circ}$. Rheinischen Friedrich-Wilhelms-Universitat, Bonn.

Zagrebelsky, G. (2008). Principî e voti . Madrid: editorial Trotta.

Zagrebelsky, G. (2005). La Corte in-politica. Quaderni costituzionali, 25(2), 273-282.

Zegrean, A. (2016). The Role of Assistants-Magistrates in the Jurisdiction of Constitutional Courts. Bucarest: Universul Juridic. 